\title{
Human conception of the environment
}

\author{
Maxim Bakhtin ${ }^{1, *}$ Nikolay Rybakov ${ }^{2}$, Natalya Yarmolich $^{2}$, and Irina Sokolovskaya ${ }^{3}$ \\ ${ }^{1}$ International Professorial Club (Italia), 97100, via Velardo, 35, Ragusa, Italia \\ ${ }^{2}$ Pskov State University, 2, Lenin Place, Pskov, 180000, Russia \\ ${ }^{3}$ State University of Management, 109542, 99 Ryazan Ave., Moscow, Russia
}

\begin{abstract}
This article focuses on the metaphysical foundations of educational philosophy. They are considered as the sources of future human modeling and the commission of certain actions. The article explores the evolution of these principles in the development of human civilization. The causality principle is considered as the entity's fundamental ontological characteristic. It suggests that a human being can realize his desire for freedom only by submitting his life to the universal objective law. In the causal perspective, any phenomenon is considered as the consequence of a cause and at the same time as the cause of some other consequence. The model of the world of primitive man could not and did not contain a picture of nature as a certain arrangement of phenomena, united by unified causeand-effect laws. However, it does not mean that our primitive ancestors did not imagine the world around them without the categories of order, just in his mind, there was a different order.
\end{abstract}

\section{Introduction}

The purpose of the article is to determine the epistemological status of the principles of normativeness and causality, the limits of their applicability in historical science, social philosophy, and educational philosophy. One of the current problems of any transitional society is the theoretical understanding of the freedom of human will and its metaphysical foundations. For this reason, the metaphysical principles of causality and normativeness act as the fundamental basis of our view and cognition of the world.

The individual thinks that the rationality of my actions is based on their motivation. While continuing to reason things out, he replies what characterizes the relationship with the situation that he is experiencing, and also he determines the outcome of his analysis of the status quo. It is clear that the movement of thought is a strictly personal thing, respectively, and the human behavior in the same position can be completely different. Philosophically, we can affirm the predestination of the givenness by the past, since the situation has developed from events that have already occurred and created, having formed together, these very circumstances. But the predetermined outcome is not the generic quality of the present. Perhaps it can be called a kind of vector, the chequered flag that stands on the way toward

\footnotetext{
* Corresponding author: universdoktor@gmail.com
} 
the fulfillment of a certain imperative that is proposed to the individual or taken by $\mathrm{him} /$ herself as a goal. So, we can say that in the present, in which we now live, there is a bridge between the givenness (the consequence of the past) and the predetermined outcome (the projection of the future). There is a real person's "electric discharge of life» who tries to connect the thread of personal existence by feverish efforts of his thoughts and his movements.

\section{Problem statement}

The purpose of this article is to consider the question of the relation between free will and the normative order, as well as the possibility of constructing social reality and a single unified world. The article concentrates on the transition from the causal order to the normative one of the historical process throughout the 20th century. It states the hypothesis that in the 20th century the world has entered the era of controlled history, and consequently the causal order is rapidly being replaced by the normative order, in which the historical process is increasingly planned and predictable, where historical events and phenomena are more likely the embodiment of a preconceived plan of action.

The predetermined outcome is much more external to the individual than the givenness; the movement toward it should rather be taken as a continual aspiration to go beyond the givenness boundaries, that is, of the sensuous lifestream. A possible way to make such attempts may be thinking and science. However, this is only a general statement; in our case, the working principle is to consider the methodological principles of thinking.

\section{Materials and methods}

The methodological basis of the work is the principle of historicism, dialectical unity, and continuity of historical epochs. The method of comparative analysis of two ontological principles, normativity and casualty is used. The following scientific methods are also used: dialectical, historical and substratum, structural and functional, systemic and variantmodeling. Methods and principles of phenomenology, historical hermeneutics, philosophical dialogue, and principles of cultural-historical comparative studies are applied.

\section{Results and discussion}

By the 20th century, human scientific thinking had built historical and socio-cultural determinism of rationalistic conclusions of classical philosophy quite thoroughly and firmly, the original sequence of this very rationality was blurred and became very dualistic content. For example, it is recognized that it is not only the theory that is rational but also the practical life of the individual that does not fit into any theoretical trenches.

I. Prigozhin noted that "Europeans live at the intersection of at least two different value systems: on the one hand, it is scientific rationality, and on the other, it is the rationality of collective behavior" [1]. Let us add to this inference that any revealed rationality is necessarily based on the certainty of some logically arranged order in the world. This postulate, in its turn, is the foundation for explaining the ontological definitions of existence, and the essence largely depends on the content of the dominant doctrines or religious views of the historical period under review. How and where do these opinions and beliefs come from, how are they transformed, and what do they turn into as a result of such transformations, asks V.V. Balakhonsky [2]?

The model of the world of primitive man could not and did not contain a picture of nature as a certain arrangement of phenomena, united by unified cause-and-effect laws. However, 
it does not mean that our primitive ancestors did not imagine the world around them without the categories of order, just in his mind, there was a different order. Marlene Belios notes: what for modern human looks like a nature separate from him and his life, it was an organic part for our ancestor's life, or, rather, he felt a part of the natural world, he was connected with it by blood vessels of beliefs, rituals, and, of course, purely material dependencies, since food, clothing, heat were taken exclusively from the natural environment [3].

Robert Talisse writes, "We do not know and will never know when it happened: at certain moments in the historical development of mankind, a social order that regulates human relations is born and further advanced will develop, so that at a certain period the whole world will obey it, and it is based not on causal (cause - consequence) but normative (blame retribution) laws" [4].

Nevertheless, modern ethnographers, based on the data of their science, claim that the ideas of human responsibility for everything that happens in the world belong to the ancient beliefs of mankind. For example, R. Gottlieb believes that he accepted the natural phenomena not as neutral to his atmospheric processes, but in a cause-and-effect relationship under the law of retribution, he took the positive natural influences as a reward and the negative ones as a deserved punishment for some wrongdoing. Thus, it was not peculiar for the primitive mind to perceive separately nature as an object of causal order and social environment with its normative structure, which is characteristic of modern Scientist thinking [5].

In general, the worldview based on normative principles does not converge cardinally with the causal one, unless we mention another type of consciousness - mythoreligious, which historically for a long time can integrate such opposite perceptions of the world. Here the contradiction is resolved simply: the sequence of natural phenomena, as well as social processes, is manifestations of the divine will, the opposition to which, however mental, entails inevitable punishment. It is symptomatic that both cause and blame are designated by one word, atria, in the ancient Greek dictionary. The transition from a normative perception of eventfulness to a causal one occurred when Homo sapiens concluded that relationships in inanimate nature, unlike human ones, are not related to either the will of man or the One above him or, in another way, they are normative. Edward Page suggests that such a leap in consciousness was certainly not easy or quick in the historical sense of the time [6].

The whole way of the genesis and development of human thought about the impersonality of the natural order, which is the ontological core of classical rationality, begins with the first philosophers of ancient Greece and over the centuries comes to the ideas of Galileo, Descartes, and Newton. V.P. Bransky argued that according to Plato's philosophical views, the world space is two-component: there is an ideal world, a certain model, the abode of pure entities and exemplary relations between them and the objective world, our earthly, that reflects the ideal model, but in comparison with it much rougher, more primitive, simpler [7]. Nevertheless, the ideal world shows us (the humans) the highest aim and marks the direction of aspiration. But it is impossible for earthly beings to embody the laws of existence, but it is possible for pure minds to comprehend them through contemplation. Melissa Seymour believes that the empiricism that fills our earthly sciences and cognition is not pure knowledge, genuine knowledge that can be obtained, again, through mental contemplation, which may eventually provide insight into the higher meanings of the world and the discovery of man's true role in the universe [8].

Still, there was not a radical separation of causality and normativity in ancient thinking. Most ancient philosophers read a certain established order in the laws of nature, and identified the category of cause with the actions of fate: "Everything happens by fate, as Chrysippus, Pocidonius, Zeno and Boethus say $<\ldots>$ Fate is the unbroken [chain] of causes of things, or the reason according to which the universe is governed" [9]. 


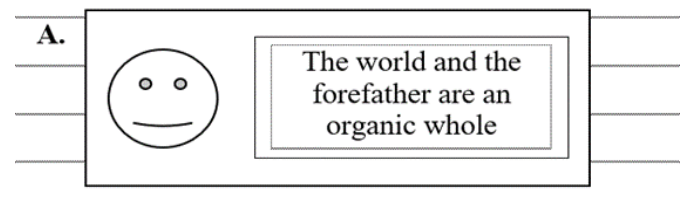

Fig. 1. Regulatory and causality merged together.

The separation of causality and normativity did not occur in the 17th century. For example, in Descartes' Discourse on Method, where he makes absolutely clear his considerations of the laws "established by God in nature" and also, in one of his letters, emphasizes the same idea that "God established these laws ... just as the sovereign establishes the laws in his kingdom" [10].

Newton concludes this historical movement of human thought from normativity to causality of the universe, he proclaims the unity of the laws of celestial and terrestrial mechanics, After the archaic model of the universe, this "pyramid" with the gods at the top, the basic for New Thinking concept of the Universe appears, where, according to Roger Morris, the mathematics that does not obey anyone describes with the same formulas the movements of heavenly bodies and the functioning of earthly processes [11].

That is, humanity's discovered vision of the world has been substantiated by a code of causal laws that are precisely expressed - once and forever! - mathematically. Who made these laws in such a way that they were taken as indisputable? Science, which at a certain point became the highest authority in the world, in many minds even, replaced God, let us not, however, and give a moral assessment of this fact, since such a task is far from the scope of our reasoning. Thus, as Laura Vestra believes, the science has taken a stand on the seat of chief arbiter capitally, this can confirm that the causal order of the world makes it possible at any time and in any place to determine precisely and equally the relations of any phenomenon to everything that has already happened and even to the future [12].

The epistemological perspective of such a worldview, which can be called dominant in the minds of mankind, is inexhaustible because it has a truly infinite resource of premises. For example, "nothing that occurs happens without a corresponding reason". Or, "surprises, until we have identified the reasons, caused them". Indur Goklany notes that we try to apply the cause-effect relationships we have already elucidated, move toward new aims, but some patterns we have not yet grasped, make this continuous movement toward progress (as we believe this view gives us strength) subject to fluctuations due to many circumstances as yet unclear to us, which undeniably reflects the thorny nature of our way [13].

However, there is also certain predestination and predetermined outcome in this inflexible causality; it was taken as the main ontological feature of existence, with the implication that a human embodies a personal desire for freedom only by accepting the lack of freedom of this law. One could also say that an individual who lives within the framework of causality must cut off everything incidental in his worldview, and leave only the necessary. Or, wishing to be free, he turns himself into an ascetic, not only in means but also in motives and aims: for his thoughts must not go beyond that would not be related to objective necessity. Thus, causal existence is strictly deterministic, and without the participation of the will itself: "Science," writes Dostoyevsky in "Notes from the Underground" "will teach human that... Everything he does is not done by the will, but by itself, according to the laws of nature. Consequently, it is only necessary to discover these laws, and human will not be responsible for his own deeds" [14].

The causal worldview appeared after a long process of forming new ideas about the model of the world. The previous world, where was the normative order of things, could be likened to a pyramid, where everything was subject to the will of a supreme being, whether Pharaoh 
or gods, but in any case, a subject. Our new universe lives according to objective laws, step by step, they are explained by science, it gives a sense of continuous human creation of a picture of the world order that extends to every particle of the cosmos, and it is not controlled by anyone or anything, but it is inherent.

The great Leibniz, who stood at the derivations of modern scientific knowledge, postulated: the prevailing order in the world is such that "every complete action represents [its] complete cause", so "from the knowledge of this action I can always come to the knowledge of its cause" [15]. If the cause is "fully represented" in the effect, then the logic of our cognition should be as interconnected as the natural cause-effect chain. Leibniz's confidence in the causality of the universe implies an unbroken chain of cause-and-effect phenomena, the kind of mathematical formula that the new Einstein is about to write on the lecture board. However, such an outcome would, by its finitude, contradict both the aforementioned scientist's theory of relativity itself and the principle of individual free will, which is still one of the mysteries of knowledge. Kant said about it as freedom, the subject to moral law - the "categorical imperative"- the believers would offer, of course, to rely on the divine will, while we, in order not to enter into endless polemics, would conclude this thought in the words of Hermann Hesse - "we are free to choose our dependencies".

The total understanding of nature today is that it looks like some kind of extra-historical education. In such a model, the full cause of any phenomenon is represented in it as a complete consequence, from which the equivalence of both factors arises. However, if the cause and effect are equivalent, we deal with the reversibility of time, naturally, in the logical conclusion.

Thus, since the periods of Modern history, about three centuries ago, this "Leibnizian" idea of the extra-historical nature of the scientific laws was discovered one after another, they are inherent, the cosmos, and the Universe, in general, has been increasingly disseminated. Note that such a vision has become universal not only among scientists and thinkers in general but also among ordinary people: causality has entered their ordinary conceptions, it has constructed the worldview as an infinite cause-and-effect chain between the past and the future.

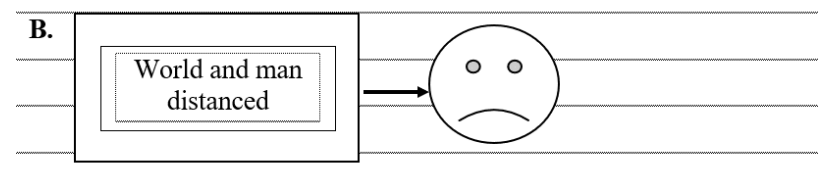

Fig. 2. Causality precedes normativeness universal determinism.

But in the recent past, there were signs of a paradigm shift: somewhere in the second half of the 20th century, at least among people of science, the concept of a total causal world order began to blur. Universal determinism no longer seems a universal law, and therefore the pillars of classical European rationalism begin to swing - the ontological law of continuity of cause-and-effect phenomena has already been described by us, as well as the following gnoseological law of the unity of the building of rational science. This is not yet very visible to the uninitiated, but within the process of cognition you can hear the panic exclamation, and now, for example, Gaston Bachelard calls Leibniz's notorious concept of universal determinism unbelievable, monstrous! [16].

Well, "all of us, all of us in this world are perishable," and as it turns out, the same applies to the seemingly firm, open, and once and for all, laws of the universe. There's nothing like that: we see today that the diffraction of the gnoseological perspective, which until recently has been strictly straightforward, and the change in ontological foundations legitimately has changed the entire construction. Because it was on this foundation that we established the main meanings of the existing order of things. The ontological foundation of the entire 
scientific edifice-the laws of nature exist «on their own», they are independent of human existence -, are now crumbling. But if this is the case, when the image of the world is disintegrated with the differentiation of natural and human existence, recently presented by one in all its structure, details, corners, is destroyed, because everywhere, as we thought, the same universal causal laws operate.

The transformation of thinking that is taking place beneath our eyes is probably similar to the revolution in consciousness that Giordano Bruno and Galileo once brought about by moving our planet from the center of the universe to an ordinary orbit. Such advances change the ruts of our thinking so that we turn where we used to pass directly, and we discover a completely new perspective, where we see something previously unseen. But these are not all the results of the shift in perspective: eventually, we feel that we find ourselves in a different, new world of other meanings. A sure sign of falling into the looking glass is that we don't care about things that used to be important and vice versa. Matthias Klim suggests that the most important change is that the principles of the universe are no longer perceived as inherent, but as something that dependents on an accepted paradigm. This acceptance is not done by painstakingly identifying causal processes, but rather by an act of will, that may seem irrational against the background of the rationality deified by previous centuries, school logic, but itis not so: we simply deal with a new type of rationality, a non-classical one. This type of thinking and acting still needs to be accustomed to, there is no other option because this choice has already been made.

However, unlike the causal order of classical rationality, the normative world order is now seen neither as an absolute and eternal characteristic of existence and thinking itself, nor as the result of some powerful transcendental power will. This order is understood as established or recognized by humans, not by a superhuman authority, and therefore it has a normative force only within the boundaries of a particular cultural community or historical epoch. In this regard, the understanding of modern history as governed history is an understanding of the new world order as normative creation. The New World Order in this interpretation is the normative will, the act of concrete people; it governs the historical process and thereby creates it. With this understanding, modern history appears as the creation, the normative act of a group of individuals with a clear plan of action (let us remember Woland's words to Berlioz about the man who is the creator of history, who does not even have a clear plan for it). The embodiment, the step-by-step implementation of this plan is nothing less than the objectification of each act of will of the designers and architects of the New World Order. Only by reaching a certain level, the degree of globalization, human history could become truly manageable, and therefore could move to a normative order. Before that, in the primitive era, that is, until 1917, human history developed chaotically, it moved more by objective historical laws. Thus, the tribal society was replaced by the slaveowning society not because some group of people wanted it, but by objective historical laws of class formation. In the same way, slave-owning society was replaced by feudal society, and the latter was replaced by capitalist society. But all these changes were not due to a normative order, that is, not due to the desire of specific individuals, but because of the objective historical and economic laws of human evolution. In other words, the development of the historical process then was casual. Jean-Werner Müller noted that the maturation of these or other historical causes gave rise to certain historical changes, the birth of new forms of world order, dialectical transitions, leaps, and bounds, etc.

On the contrary, capitalism's achievement of its new phase of development, imperialism, ensured such a concentration of production and capital on the planet that globalization after World War I proceeded at a much faster pace than before. From that moment on, the casual order began to be rapidly replaced by the normative order and is being replaced by it more and more. Thus, the concentration of the historical process in the hands of a narrow circle of monopolists ensures the transition of the casual order of social life and history to a normative 
order. And the greater this concentration, the greater the degree and severity of controllability of the historical process, the sooner the transition from the causal to the normative order will take place. A clear example of such a transition is the special operation of the architects of the historical process, codenamed "coronavirus" or "pandemic," unprecedented in its scale and scope. The highest degree of manipulation and zombification of society is manifested in the fact that in the absence of any pandemic in 2020 the authors of this special operation were able to assure $99 \%$ of the world population of the existence of this very pandemic and its danger. At the end of 2021, according to official data, about 170 million people, that is, only 3 percent of people, are officially infected with the coronavirus.

The second indicator of the epidemic is mortality. History gives us a lot of evidence of large-scale epidemics from antiquity to the present day. As a rule, large-scale epidemics claimed the lives of 0.5 to $5 \%$ or more of the population. That is, with a population of one billion in the early XX century, large-scale epidemics killed 5-10 million people, and Spanish influenza (1914-1918) - 50-100 million people, that is, 5-10\% of the population. In this respect, the modern imaginary "pandemic" also cannot withstand comparisons with the largescale epidemics that plagued humanity in the past. In 2020-2021, more than four million people died of coronavirus, far fewer than deaths from pneumonia, malaria, cholera, typhoid, and other epidemics.

All this suggests that the directors of the modern historical process have superpower methods of manipulating the minds of the masses and indoctrinate them into any idea, even the most absurd, which contradicts the obvious facts. Moreover, not only the masses have been manipulated, but also significant segments of scientific and pedagogical personnel, who, contrary to the obvious, have blindly repeated to the mass media (or rather, misinformation) about some kind of "pandemic".

Another indicator of the normative order of the historical process is the rather long time interval between the creation of the plan for the development of history and its implementation. As you know, a more or less formalized plan for the New World Order was drawn up after World War II, in 1945-1950, when the outlines of a bipolar world appeared in its general terms. Many of the events and phenomena of the modern world that we are witnessing today were designed 75 years ago, at the dawn of the bipolar era. This indicates that the normative order by which these plans are embodied is increasingly changing the order, where the only cause of events and phenomena should be objective causes.

The normative order constructs not the only history that is, the historical dimension of human existence, but also the social structure. In the primitive epoch of pre-modern history, until the beginning of the XX century, the construction of the social structure was carried out by objective causality, that is, by the casual order. The development of productive forces provided a surplus, and, consequently, the emergence of private property, the need to release some individuals, the ruling class from the direct production process. This is how formations and ways of life changed, and all these happened not by anyone's will, but because of a whole set of objective laws of economics and history. Of course, the subjective factor has always played an important role in history, but not a decisive one. The subjective factor could cause an uprising, a coup d'état, but not a revolution. It was only on the threshold of the era of guided history, in 1917, the subjective factor first began to "compete" with objective factors. For example, the mighty superhuman will and tremendous authority of Bolshevik leader V.I. Lenin played a decisive role in the organization and preparation of the October 25, 1917, armed uprising in Petrograd. Ilyich's famous phrase «one who hesitates is lost" was a vivid characteristic of the historical situation at the time. The bifurcation point of history that day was so clear that much was depended on who would be the first to take power and lead Russia along one or another historical path. Then the subjective factor spurred the objective laws of historical development, literally accelerated the course of history. This was not the first time 
in Russian history. The same thing A.S. Pushkin said about Peter the Great: "gave the run of the ship of his own".

The continued increase in the concentration of capital on the planet led to a situation in the middle of the XX century when guided history became not only possible but necessary. Finally, for the first time, humanity approached the possibility of creating a United World without Political Borders or National Government. At the beginning of the 21 st century, new technological possibilities have emerged, and the 6th technological way has begun to take shape when most of the physical labor will be performed by robots. This opportunity has led to the need to construct a new social structure. The need for the middle class has now disappeared. There is still a need for highly skilled work of a limited number of people. From that point on, the normative order began to dominate the casual order more and more. On the agenda was the creation of a single integrated world with a single world government, currency, legislation, etc. Humanity has come very close to the question of what kind of force will emerge as the architect and designer of this United World.

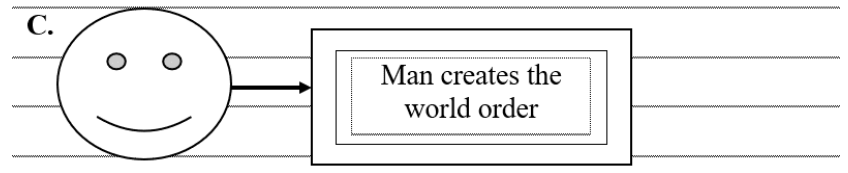

Fig. 3. Regulatory creativity is the basis of the caustic world order.

The intrinsic difference between causality and normativity as principles of world order organization is, first of all, the following. From the causal perspective, any phenomenon is considered as a consequence of some cause and at the same time as the cause of some other consequence, so the cause-and-effect chain is presented as a solid, unbroken line that starts from infinity and goes to infinity. The normative perspective, unlike the causal one, presupposes quite a definite beginning - the very creative act of free choice of metaparadigmatic attitude, which sets the boundary conditions of functioning not only of a certain type of thinking but also of the life of the social organism as a whole. It is in this fundamental distinction between causality and normativity that the opposition between state necessity and human freedom is rooted in nature. The fact that a human is free means that he can assert that these or those norms, he can be the initial (first) link in a certain causal chain. In making this kind of decision, he acts as a cause of the effects, but not as a consequence of the cause. This understanding of freedom is fundamentally different from the " cognized necessity " of the causal tradition.

The development of the cause-and-effect series occurs as a smooth transition from one possible world to another. The act of freedom is a break in gradualism that irreversibly transports us into another world, immediately created by this very act. And here we are not talking about the cause, but rather the guilt. We are responsible for this transition, we have created this world and we are responsible for the fact that it now exists. At the same time, the guilt is not understood in the moral-evaluative sense, but in the ambivalent (metaphysical) sense, for the birth of good or evil out of our deeds is equally likely. Therefore, responsibility does not mean punishment, but the consciousness of one's active participation in life, one's involvement in existence.

\section{Conclusions}

So, having lived through centuries of creation of the "encyclopedia of nature," where everything under the causal principle was built on cause-and-effect relationships and tried to project this construction further onto the society, we realized the unreality of understanding 
of being a simple displacement the normative order with the casual one. However, the opposite movement of thought, a return to normativity due to the abandonment of causality seems just as untenable. To avoid such a fruitless dilemma means to recognize the multidimensionality of the world, which means that there is no one universal way-the "key"to both the mysteries of nature and the intricacies of social processes. While we are looking for a new concept that integrates these two methods of cognition, one of which is based on the sequence of what happens after the preceding, and the other speaks about the personal choice of action.

\section{References}

1. I. Prigozhin, Science, Civilization and Democracy (Philosophy and Sociology of Science and Technology: Yearbook, 1988 - 1989. - M., 1989)

2. V.V. Balakhonsky, Explanation of history: historical-philosophical, methodological and epistemological aspects (SPb .: RGPU im. A.I. Herzen; Penza: PSPU im. V.G. Belinsky, 1997)

3. M. Belilos, Freud and war (London, 2018) https://doi.org/10.4324/9780429474996

4. R. Tallise, Democracy After Liberlism. Pragmatism and Deliberative Politics (New York, 2005) https://doi.org/10.4324/9780203997680

5. R. Gottlieb, Environmental Crisis and Moral Life. In morality and the Environmental Crisis, Cambridge Studies in Religion, Philosophy and Society (Cambridge, Cambridge University Press, 2019) https://doi.org/10.1017/9781316493083.002

6. A. Edward, Page Climate change, Justice and future Generetions (Cheltenham, UKNorthampton USA, 2006) https://doi.org/10.4337/9781845424718

7. V.P. Bransky, The problem of the meaning of history (Art and Philosophy. - Kaliningrad: Amber Garden, 2006)

8. M. Seymour, F. Love, Respect and Interfering with other, Pasific Philosophical Quarterly 92, 2, 174-192 (2011) https://doi.org/10.1111/j.1468-0114.2011.01390.x

9. Fragments of the early Greek philosophers. - Translation / USSR Academy of Sciences, Institute of Philosophy. Edition pod. A.V. Lebedev. Resp. ed. and the author will enter. articles by I.D. Rozhansky (M.: Nauka, Part 1. From epic cosmogonies to the emergence of atomism, 1989)

10. P. Berger, T. Lukman, Social construction of reality: A treatise on the sociology of knowledge (M.: Madium, 2009)

11. R.S. Morris, Diseases, dilemmas decisions - Converting epidemiological dilemma into successful disease control decisions, Preventive Veterinary Medicine 122, 1-2, 242-252 (2015) https://doi.org/10.1016/j.prevetmed.2015.05.003

12. L. Westra, Environmental Justice and the rights of Ecological Refugees (London, 2009) https://doi.org/10.4324/9781849770088

13. G. Leibniz, Works (M.: Nauka, 1984)

14. G. Bashlyar, Rational determinism and technical determinism (Philosophy and sociology of science and technology. M.: Nauka, 1986)

15. M. Kline, Mathematics. Loss of certainty (M.: Nauka, 1984)

16. M. Kimm, Why Europeans will not embrace constitutional patriotism? International $\begin{array}{lllll}\text { Journal of Constitutional } & \text { Law }\end{array}$ (2008) https://doi.org/10.1093/icon/mom034 
17. J.-W. Muller, Constitutional Patriotism (Princeton University Press, 2008) https://doi.org/10.1515/9781400828081 